\title{
Molecular detection of Salmonella enterica serovar Typhi by Vi-qPCR
}

Nik Noorul Shakira Mohamed Shakrin ${ }^{\star *}$, Siti Noor Adnalizawati Adnan², Asmah Hani Abdul Wahab ${ }^{3}$, R. Pusparani Ramasamy ${ }^{3}$, Wan Noraini Wan Yussof ${ }^{3}$, Noorliza Noordin ${ }^{3}$, Khebir Verashahib ${ }^{3}$, Rohani Jahis ${ }^{4}$

${ }^{1}$ Faculty of Medicine and Defence Health, Universiti Pertahanan Nasional Malaysia (UPNM), 57000 Sungai Besi, Kuala Lumpur, Malaysia.

${ }^{2}$ Faculty of Dentistry, Universiti Sains Islam Malaysia (USIM), Level 15, Tower B, Persiaran MPAJ, Jalan Pandan Utama, 55100 Kuala Lumpur, Malaysia.

${ }^{3}$ Bacteriology Section, National Public Health Laboratory, Lot 1853, Kampung Melayu, 47000 Sungai Buloh, Selangor, Malaysia.

${ }^{4}$ Bahagian Kawalan Penyakit, Kementerian Kesihatan Malaysia, Blok E10, Kompleks E, 62590 Putrajaya, Malaysia. Email: shakira@upnm.edu.my

\begin{abstract}
Aims: To develop a real-time polymerase chain reaction system Vi-qPCR in the detection of Salmonella enterica serovar Typhi ( $S$. Typhi), targeting the vexC gene encoding for $\mathrm{Vi}$ antigen (capsular polysaccharide antigen) and to evaluate its sensitivity and specificity performance using pure cultures of $S$. Typhi and other enteric pathogens.

Methodology and results: Microbiological, biochemical and serotyping tests were conducted to determine the phenotypic characteristics of $S$. Typhi and other enteric pathogens in our collection. Primers were designed using Primer3 software and their in-silico specificity were analysed using Basic Local Alignment System Tool (BLAST). Optimisation of PCR annealing temperature was done prior to assessment of sensitivity and specificity performance against artificial serially diluted seeded stools. The primers were found to be $100 \%$ specific in the detection of $S$. Typhi towards 32 tested clinical strains. Verification of gene amplification by comparing the nucleotide sequences against reference genes in the GenBank database revealed high specificity to $S$. Typhi. Statistical analysis indicates that this method results in $100 \%$ sensitivity, specificity, positive predictive value (PPV) and negative predictive value (NPV). Moreover, Vi-qPCR allows the detection of $S$. Typhi as low as $13 \pm 1.4 \mathrm{CFU} / \mathrm{g}$ of stool sample.

Conclusion, significance and impact of study: A rapid and sensitive method for detection of Salmonella enterica serovar Typhi ( $S$. Typhi) is desired as a diagnostic tool to improve typhoid management. The Vi-qPCR represent a promising non-invasive diagnostic tool for medical microbiology laboratories as a method for the detection of $S$. Typhi in both pure culture and stool specimens especially in chronic asymptomatic carriers where shedding of $S$. Typhi is intermittent and sometimes occurs in low level.
\end{abstract}

Keywords: PCR, diagnostic, pathogen

\section{INTRODUCTION}

Typhoid fever is one of the most common foodborne illnesses caused by the Gram-negative bacterium, Salmonella enterica serovar Typhi (S. Typhi). The disease continues to be a global public health problem particularly in countries with poor sanitary conditions and hygiene standards (Crump et al., 2004; Brooks et al., 2005). It was estimated that this pathogen causes 21.6 million cases with 216,000 deaths each year worldwide (Crump et al., 2010). The majority of cases and deaths are in Asia countries. The remaining cases occur mainly in Latin America and Africa. The incidence of typhoid fever is low in industrialised countries and commonly associated with travel history to endemic regions (Parry et al., 2011).
Salmonella enterica serovar Typhi can be transmitted via fecal-oral route. It is usually associated with consumption of contaminated water and food. After ingestion, colonisation of the small intestine will be initiated by invasion of the gastrointestinal mucosal surface. Subsequently, dissemination of the pathogen throughout the body in the reticulo endo-thelial system that includes the liver, spleen and bone marrow will take place. A person can be a long term chronic fecal shedding host due to relapse and $S$. Typhi carriage in gall bladder. Asymptomatic carriers play an important role in perpetuating the disease and are responsible for typhoid outbreaks. The signs and symptoms of typhoid may mimic other diseases including leptospirosis, malaria, dengue and rickettsioses. The unspecific signs and symptoms therefore complicate the clinical diagnosis (Feasey et al., 2012; Wain et al., 2015). 
Currently, the gold standard method for typhoid diagnosis is the culture method. This method is timeconsuming in view of requiring two to five days to produce results. Moreover, this method has poor sensitivity which depends to the type of samples used (30-60\%). Detection of $S$. Typhi from bone marrow sample was reported to give the highest sensitivity compared to other types of samples (Wain et al., 2001; WHO, 2003; Bhutta, 2006). Culture methods are highly depended on viability of targeted bacteria in the samples. In situations where the patient has received antibiotics prior to specimen collection, negative culture results will be obtained. This was reported to be one of the major obstacles in $S$. Typhi diagnosis (Tennant et al., 2015; Wain et al., 2015).

There are several serological methods for typhoid diagnosis such as Widal test, Typhi-Dot, Tubex (Naheed et al., 2008) and lateral flow (Nakhla et al., 2011). These immunological methods were designed based on the types of $S$. Typhi $\mathrm{O}$ and $\mathrm{H}$ antigens. Despite their rapidity and simplicity, the tests are not suitable for typhoid early prevention. In addition, these assays also are relatively low in sensitivity. They are prone to be influenced by the phases of the disease. The interpretation of the immunological reaction depends on the antibody production and its titre. The antibodies are normally induced at least one week after $S$. Typhi infection. Thus, there is an urgent need for the development of a rapid and reliable test to detect this food-borne pathogen for prevention and effective management of typhoid especially during outbreaks.

Polymerase chain reaction (PCR) has been successfully used to detect bacterial pathogens in clinical samples, aquatic environments and food products (Moganedi et al., 2007; Elizaquivel and Azhar, 2008; Park et al., 2009; Kumar et al., 2010; Fan et al., 2015). In conventional PCR, amplicon is detected by agarose gel electrophoresis whilst in real-time PCR, the PCR product is quantified by measuring the fluorescent signal. Realtime PCR has several advantages over conventional PCR which are more rapid and robust. These criteria contribute in less variability in the assay as well as the interpretation. The real-time PCR method was reported to have advantages over the culture method for detection of $S$. Typhi in sensitivity as well as specificity and require shorter time for analysis (Wang et al., 1997; Ambati et al., 2007; Levy et al., 2008; Ali et al., 2009; Germini et al., 2009; Zhang et al., 2014). In this study, a real-time PCR assay targeting the $S$. Typhi vexC gene that encodes the $S$. Typhi Vi antigen (capsular polysaccharide antigen) was developed. The Vi antigen was previously suggested as a specific target for the identification of $S$. Typhi due to its association with virulence (Hashimoto et al., 1995; Sharma et al., 1995; Hirose et al., 2002; Farrell et al., 2005). The antigen modulates several pro-inflammatory signalling pathways of macrophages, dendritic cells and microfold cells (Schadich et al., 2016). Hence, this study aims to develop Vi-qPCR and evaluate the performance using pure cultures of $S$. Typhi and other enteric pathogens. In addition, the sensitivity of the optimised methods was further evaluated using artificially seeded stool samples with similar strains of bacteria that also included Vi-possessed bacteria, Citrobacter freundii (Kolyva et al., 1992).

\section{MATERIALS AND METHODS}

\section{Bacterial strains}

A total of 32 bacterial strains were used in this study as listed in Table 1. All strains were obtained from National Public Health Laboratory (NPHL), Ministry of Health Malaysia's culture bank. A Salmonella enterica serovar Typhi TP279 (Bionumber 0015610540144200) was used as positive control throughout the experiments. Identifications of positive control strain and other strains used in this study were carried out by means of standard microbiological and biochemical methods using Vitek®2 compact system (bioMérieux, France). Serotyping of the strains was performed by slide agglutination following the manufacturer's instructions (Staten Serum Institute, Denmark).

\section{Bacterial DNA extraction}

All bacterial strains were grown overnight (18-24 h) on blood agar (BA) medium (Thermo Fisher Scientific, Malaysia) at $35{ }^{\circ} \mathrm{C} \pm 2{ }^{\circ} \mathrm{C}$. Genomic DNA of the strains were extracted using QIAmp® DNA Mini Kit (Qiagen, Germany) following the manufacturer's instructions. DNA concentrations and purity were determined spectrophotometrically using a biophotometer (Eppendorf, Germany). The presence and quality of intact DNA was visualised on $0.8 \%$ agarose gel stained with GelRed ${ }^{\mathrm{TM}}$ (Biotium $\AA$, USA). The DNA was stored in $-20{ }^{\circ} \mathrm{C}$ until further use.

\section{Primer design}

Primers were designed using Primer3 software (http://bioinfo.ut.ee/primer3-0.4.0/) based on the vexC gene of $S$. Typhi (GenBank Accession Number AL513382). Both forward and reverse primers were respectively named as SViF and SViR. These primers were expected to generate a $300 \mathrm{bp}$ nucleotide product. In silico specificity of the primers were analysed using Basic Local Alignment System Tool (BLAST) from the GenBank at http://blast.ncbi.nlm.nih.gov. Details of the primers are as in Table 2.

\section{Conventional PCR optimisation}

The initial part of PCR optimisation was performed using conventional PCR. The S. Typhi TP279 DNA was used as template throughout the optimisation. Each reaction in a total of $25 \mu \mathrm{L}$ contained $12.5 \mu \mathrm{L}$ PCR Master Mix (Promega, USA), $1 \mu \mathrm{L}$ each of the forward and reverse primers, $5 \mu \mathrm{L}$ of DNA template and $5.5 \mu \mathrm{L}$ molecular grade water. The primer concentration used in the reaction was kept constant at $10 \mu \mathrm{M}$. Amplification was performed in Mastercycler Nexus (Eppendorf, 
Germany). Annealing temperature optimisation was performed at 12 points using the following condition; initial denaturation at $94{ }^{\circ} \mathrm{C}$ for 2 min followed by 35 cycles of $94{ }^{\circ} \mathrm{C}$ denaturation for $1 \mathrm{~min}$, annealing at $49.8^{\circ} \mathrm{C}$ to 65.1 ${ }^{\circ} \mathrm{C}$ for $1 \mathrm{~min}$ and extension, $72{ }^{\circ} \mathrm{C}$ for $1 \mathrm{~min}$. PCR products $(5 \mu \mathrm{L})$ were electrophoresed on $2 \%$ agarose gel in a $0.5 \times$ TBE buffer at $85 \mathrm{~V}$ for $60 \mathrm{~min}$. The gel was stained with GelRed ${ }^{\mathrm{TM}}$ (Biotium ${ }^{\circledR}$, USA). A 100 bp DNA ladder (Fermentas, USA) was included as the molecular weight marker in every electrophoresis run. The PCR products were visualised under ultraviolet (UV) illumination using gel image documentation system (GelDoc 1000 system, Bio-Rad, USA). Optimised parameters (annealing temperature) by conventional PCR were used in subsequent experiments for real-time PCR.

\section{Real-time PCR (Vi-qPCR)}

Real-time PCR was carried out in LightCycler $^{\circledR} 480$ (Roche, USA). The reaction mix consisted of $10 \mu \mathrm{L}$ of LightCycler® 480 SYBR Green I Master (Roche, USA), $1.0 \mu \mathrm{L}$ of each forward and reverse primers $(10 \mu \mathrm{M}), 5 \mu \mathrm{L}$ of DNA template and $3 \mu \mathrm{L}$ molecular grade water. The thermal cycling protocol of the assay consisted of $5 \mathrm{~min}$ pre-incubation at $95{ }^{\circ} \mathrm{C}, 40$ cycles of PCR amplification $\left(95^{\circ} \mathrm{C}\right.$ for $10 \mathrm{sec}, 60^{\circ} \mathrm{C}$ for $10 \mathrm{sec}$, and $72^{\circ} \mathrm{C}$ for $10 \mathrm{sec}$ ), post-amplification melting $\left(95^{\circ} \mathrm{C}\right.$ for $5 \mathrm{sec}, 65^{\circ} \mathrm{C}$ for 1 min) and a cooling step $\left(40^{\circ} \mathrm{C}\right.$ for $\left.30 \mathrm{sec}\right)$.

\section{Verification of vexC amplification}

Verification of primer amplification was performed by sequencing the PCR product of S. Typhi TP279 $\left(1^{\text {st }}\right.$ Base Sdn. Bhd., Malaysia). The sequence was then analysed using Basic Local Alignment Search Tool (BLAST) nucleotide database (http://blast.ncbi.nlm.nih.gov).

\section{Vi-qPCR specificity assessment}

Specificity of SViF and SViR primers were assessed towards known $S$. Typhi, other enteric pathogens strains and gastrointestinal normal flora (Table 1) by employing an optimised Vi-qPCR conditions. The experiment was repeated three times to ensure reproducibility.

\section{Evaluation of Vi-qPCR detection limit}

Detection limit of the assay was evaluated against extracted DNA from a serially diluted seeded stool of $S$. Typhi TP279 culture (in selenite F) as described by Fan et al. (2015). The detection limit of Vi-qPCR was defined as the lowest CFU of $S$. Typhi that could be detected. Briefly, a mid-log phase culture of $S$. Typhi TP279 [approximately $1 \times 10^{9} \mathrm{CFU} / \mathrm{mL}, \mathrm{OD}_{600} 0.8$ ) in tryptone soy broth (TSB) (Difco Laboratories, Detroit, USA) was ten-fold serially diluted $\left(10^{8}\right.$ to $\left.10^{0} \mathrm{CFU} / \mathrm{mL}\right)$ in sterile phosphate-buffered saline (PBS) $\mathrm{pH}$ 7.3]. A total of $200 \mu \mathrm{L}$ of each dilution culture was then mixed with $0.2 \mathrm{~g}$ stool of a healthy person. Thus, $1 \times 10^{8}$ to $1 \times 10^{0} \mathrm{CFU} / \mathrm{g}$ of $S$. Typhi seeded stool samples were obtained. Five millilitre of selenite $F$ broth was added to each of the spiked stool sample, mixed well and incubated overnight at $35{ }^{\circ} \mathrm{C} \pm 2$. Non spiked stool with sterile PBS pH 7.3 served as negative control. Quantification of actual CFU used to the spike stool samples was determined by performing viable counts. The assay and viability count tests were performed in duplicate to achieve the optimum fidelity. Pre-treatment of the sample was done prior to the procedures. The selenite $\mathrm{F}$ broth culture was centrifuged at $4{ }^{\circ} \mathrm{C}, 6000 \times g$ for $15 \mathrm{~min}$. Collected pellet was washed with $1 \mathrm{~mL}$ of sterile phosphate buffer saline (PBS) $\mathrm{pH} 7.3$ and centrifuged for 2 min. Template DNA was then extracted from the harvested pellet by using $\mathrm{QIAmp} \AA$ DNA Stool Mini Kit (Qiagen, Germany) according to the manufacturer's instructions.

\section{Statistical analysis}

Specificity, sensitivity, negative predictive value (NPV) and positive predictive value (PPV) of the developed assay were statistically analysed using the formula as described by Parikh et al. (2008) which is also available at the MedCalc.net website (https://www.medcalc.net/tests/diagnostic test.php).

\section{RESULTS}

\section{Optimisation of PCR}

Primer set SVi was used to amplify S. Typhi TP279 DNA template by targeting the vexC gene. The annealing temperature at $60 \stackrel{\circ}{\circ}$ provided the highest intensity single $300 \mathrm{bp}$ amplicon in conventional PCR (Figure 1). This annealing temperature was chosen for subsequent DNA amplification in real-time PCR. Sequencing analyses of the positive control PCR product led to the highest predicted specificity (99\%) to $S$. Typhi Vi antigen genes (vexC), GenBank Accession Numbers CP012151, CP012091, AL513382, CP003278, CP002099, AE014613 and D14156.

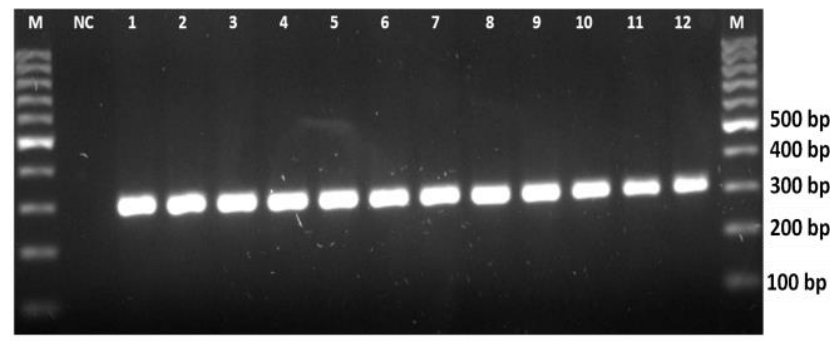

Figure 1: Agarose gel electrophoresis of Vi-PCR amplicons of $S$. Typhi TP279 at different annealing temperatures.

M: 100 bp molecular weight marker; NC: negative control; lane 1: $49.8^{\circ} \mathrm{C}$; lane $2: 50.2^{\circ} \mathrm{C}$; lane $3: 51.1^{\circ} \mathrm{C}$; lane 4 : $52.5^{\circ} \mathrm{C}$; lane 5: $54.3^{\circ} \mathrm{C}$; lane $6: 56.2^{\circ} \mathrm{C}$; lane $7: 58.3^{\circ} \mathrm{C}$; lane 8: $60.2^{\circ} \mathrm{C}$; lane $9: 62.0^{\circ} \mathrm{C}$; lane $10: 63.5^{\circ} \mathrm{C}$; lane 11 : $64.6{ }^{\circ} \mathrm{C}$; lane $12: 65.1^{\circ} \mathrm{C}$. 
No amplification was observed from PCR of the negative control stool sample. The results proved that SViF and SViR primers are specific for S. Typhi detection. The Vi-qPCR results were defined as positive or detected for a $C_{p}$ value less than or equal to 35 with a $T_{m}$ (melting curve) value of $85.0 \pm 0.5$ (Figure 2 ).

\section{Analytical specificity}

Vi-qPCR assay performed on known genomic DNAs of $S$. Typhi and non $S$. Typhi strains resulted in $100 \%$ specificity. Genomic DNA from all $S$. Typhi strains yielded positive results. Negative results were observed from PCR of other 27 non S. Typhi isolates. Therefore, the sensitivity as well as NPV and PPV of the assay are $100 \%$ respectively. The results indicate specific detection of $S$. Typhi.

\section{Vi-qPCR detection limit}

Positive Vi-qPCR results were observed for genomic DNAs from $1 \times 10^{9} \mathrm{CFU} / \mathrm{g}$ to $1 \times 10^{1} \mathrm{CFU} / \mathrm{g}$ seeded stool of S. Typhi TP279 (Table 3). There were also good concordances between the actual CFU in the serially diluted samples and the viable count results. No amplification was detected from the negative control stool sample (Figure 2).

\section{DISCUSSION}

Typhoid by $S$. Typhi remains as an important health problem especially in developing countries including Malaysia. The emergence and spread of multi-drug resistant (MDR) $S$. Typhi worsened the situation, contributing to morbidity and mortality (Kumar et al., 2008; Zaki et al., 2011). The spread of MDR strains may also introduce increment in treatment cost due to the need of powerful and expensive antibiotics.

Rapid and reliable method for $S$. Typhi detection is crucial to detect $S$. Typhi in patients and to identify the carrier. Detection of $S$. Typhi in the carrier will break the infection cycle by inhibiting the pathogen transmission and help in early typhoid prevention. A good diagnostic tool is important for effective typhoid treatment. Due to varied presentations of the disease and flaws of culture method as well as serological method, there is a delay in typhoid diagnosis and there is a possibility for few cases to be remained under diagnosed. Polymerase chain reaction is a rapid, reproducible, specific and sensitive assay. Several PCR methods have been established for $S$. Typhi detection targeting a number of genes such as the flagella genes (Song et al., 1993; Massi et al., 2003; Hatta et al., 2007; Fan et al., 2015; Chaudhry et al., 2010), tyv, prt, groEL, (Ali et al., 2009), Vi capsular gene viaB (Nizami et al., 2006), the 16sRNA (Zhu et al., 1996) and 23S rRNA genes (Pui et al., 2011).

Nested-PCR was utilised to increase the sensitivity. Unfortunately, this technique is complicated, very sensitive and usually introduces inherent problems with unspecific amplification and contamination. In addition, the use of conventional PCR in a number of studies require additional step for post-amplification agarose gel analysis. Loop-mediated isothermal amplification (LAMP) technique by Abdullah et al. (2014) was reported to have higher sensitivity and specificity for detection of $S$. Typhi in comparison to conventional PCR assay. The test is able to detect up to $20 \mathrm{CFU} /$ reaction of $S$. Typhi. However, this method is only recommended for screening purpose. Thus, further confirmation with gold standard methods such as culture method and PCR are required.

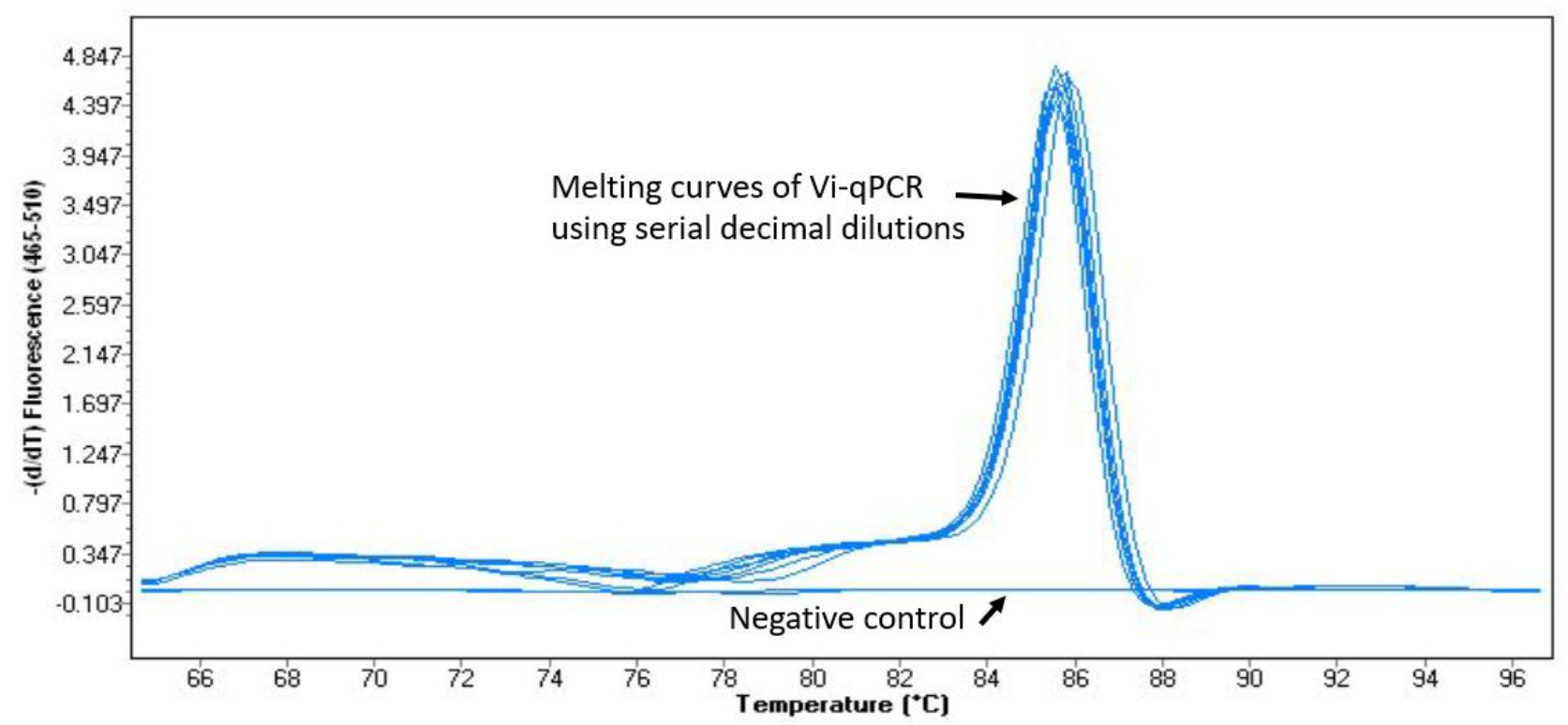

Figure 2: Melting curves of Vi-qPCR assay using serial decimal dilutions $\left(1 \times 10^{9} \mathrm{CFU} / \mathrm{g}\right.$ to $1 \times 10^{1} \mathrm{CFU} / \mathrm{g}$ seeded stool of S. Typhi TP279). 
Table 1: Bacterial strains used for the Vi-qPCR assessment.

\begin{tabular}{|c|c|c|}
\hline No. & Strains & $\begin{array}{c}\mathrm{Vi-} \\
\text { qPCR } \\
\text { result }^{\mathrm{a}} \\
\end{array}$ \\
\hline 1 & Aeromonas hydrophila ATCC ${ }^{\mathrm{b}} 7965$ & - \\
\hline 2 & Escherichia coli ATCC 25922 & - \\
\hline 3 & Escherichia 0157 & - \\
\hline 4 & Escherichia coli EPEC & - \\
\hline 5 & Escherichia coli 0104 & - \\
\hline 6 & Klebsiella pneumoniae & - \\
\hline 7 & Proteus mirabilis & - \\
\hline 8 & Salmonella typhimurium ATCC 14028 & - \\
\hline 9 & Salmonella enterica serovar Weltevreden 1 & - \\
\hline 10 & Salmonella enterica serovar Weltevreden 2 & - \\
\hline 11 & Salmonella enterica serovar Weltevreden 3 & - \\
\hline 12 & Salmonella enterica serovar Weltevreden 4 & - \\
\hline 13 & Salmonella enterica serovar Weltevreden 5 & - \\
\hline 14 & Salmonella enterica serovar Weltevreden 6 & - \\
\hline 15 & Salmonella enterica serovar Weltevreden 7 & - \\
\hline 16 & Salmonella enterica serovar Typhi TP279 & + \\
\hline 17 & Salmonella enterica serovar Typhi 1 & + \\
\hline 18 & Salmonella enterica serovar Typhi 2 & + \\
\hline 19 & Salmonella enterica serovar Typhi 3 & + \\
\hline 20 & Salmonella enterica serovar Typhi 4 & + \\
\hline 21 & Shigella sonnei & - \\
\hline 22 & Shigella flexneri & - \\
\hline 23 & Shigella boydii & - \\
\hline 24 & Shigella dysenteriae & - \\
\hline 25 & Vibrio cholerae Ogawa & - \\
\hline 26 & Vibrio cholerae Non 01/Non 0139 & - \\
\hline 27 & Vibrio cholerae Bengal & - \\
\hline 28 & Vibrio cholerae Inaba & - \\
\hline 29 & Vibrio parahaemolyticus & - \\
\hline 30 & Citrobacter freundii 1 & - \\
\hline 31 & Citrobacter freundii 2 & - \\
\hline 32 & Citrobacter freundii 3 & - \\
\hline
\end{tabular}

${ }^{a} A$ positive PCR result was indicated by crossing point value $\left(C_{p}\right)$ value less or equal to 35.0 with melting curve value $85.0 \pm 0.5$, ${ }^{\mathrm{b}}$ American Type Culture Collection.

Table 2: Details of primers designed and used this study.

\begin{tabular}{clcc}
\hline $\begin{array}{c}\text { Primers } \\
\text { name }\end{array}$ & \multicolumn{1}{c}{$\begin{array}{c}\text { Primers sequence } \\
\left(5^{\prime}-3^{\prime}\right)\end{array}$} & Target & $\begin{array}{c}\text { Amplicon } \\
\text { size }\end{array}$ \\
\cline { 1 - 2 } SViF & $\begin{array}{l}\text { GTTGCCTGCGCTAAA } \\
\text { TCTTC }\end{array}$ & \multirow{2}{*}{ vexC } & $300 \mathrm{bp}$ \\
\cline { 1 - 2 } SViR & $\begin{array}{l}\text { GACCCAGCTTGAACA } \\
\text { GTGCT }\end{array}$ & & \\
\hline
\end{tabular}

In this study, a test named as Vi-qPCR based on realtime PCR platform was developed. Real-time PCR eliminates post-amplification agarose gel analysis thus requires shorter time. This assay produces higher throughput compared to conventional PCR and reduces the possibility of carryover contamination. The Vi-qPCR provides rapid result within approximately $3 \mathrm{~h}$ including the DNA extraction step per sample. This is an added advantage especially during an outbreak when noninvasive sample collection and rapid results are required to contain the disease. In addition, the test is specific for only $S$. Typhi detection and is confirmed by the in-vitro and in-silico analysis. This assay was designed based on detection of the specific DNA sequence of the vexC gene encoding the $\mathrm{Vi}$ antigen which is located on the ViaB region. The amplification with the primer set, SViF and SViR led to highly specific results for $S$. Typhi detection. In fact, this method demonstrated negative results for all tested Vi-negative strains. A whole-genome sequencing study of $S$. Typhi has revealed the presence of 601 genes on 82 genetic islands which were absent in the $S$. Typhimurium genome (Parkhill et al., 2001). Salmonella pathogenicity island 7 (SPI-7) occupy most of these islands and consists of $S$. Typhi-specific DNA and ViaB region that is responsible for the production of $\mathrm{Vi}$ antigen (Hashimoto et al., 1993). In order to assess the ability of the test in S. Typhi detection of stool samples, the ViqPCR assay was challenged with serially diluted spiked stool. The test was able to detect up to $13 \pm 1.4\left(1 \times 10^{1}\right) \mathrm{S}$. Typhi CFU/mL in stool sample. A study by Kumar et al. (2006) reported that their multiplex PCR test could detect down to $10^{-1}$ bacteria (70 CFU/100 mL) in water samples, $4.8 \times 10^{1} \mathrm{CFU} / \mathrm{mL}$ bacteria in milk and $2.0 \times 10^{1} \mathrm{CFU} / \mathrm{mL}$ bacteria in meat rinse samples. Later, Hatta et al. (2007) developed a nested PCR for the detection of $S$. Typhi and suggested that most of typhoid patients excreted high number of $S$. Typhi in their urine or stools. The nested PCR was able to detect the $S$. Typhi DNA more in the urine $(65.6 \%)$ than in stool samples $(39.5 \%)$ of the patients diagnosed with typhoid fever. The sensitivity is lower compared to Vi-qPCR that was developed in this study. The detection limit of Vi-qPCR is acceptable and advantageous. It has been reported that depending on composition of normal flora, nutrition lifestyle and environment of the patient, stool samples contain highly variable components. The components such as bile salts, polysaccharides from vegetables, haemoglobin, heparin urea and glycolipids are potential PCR inhibitors (Oikarinen et al., 2009; Schrader et al., 2012). Presence of inhibitors may reduce PCR sensitivity (Hatta et al., 2007; Oikarinen et al., 2009).

Table 3: The growth and Vi-qPCR detection of $S$. Typhi in artificially seeded stool of selenite F culture.

\begin{tabular}{|c|c|c|c|c|c|c|c|c|c|c|}
\hline $\begin{array}{l}\text { S. Typhi } \\
\text { CFU/g }\end{array}$ & $\sim 1^{\prime} 10^{9}$ & $1^{\prime} 10^{8}$ & $1^{\prime} 10^{7}$ & $1^{\prime} 10^{6}$ & $1^{\prime} 10^{5}$ & $1^{\prime} 10^{4}$ & $1^{\prime} 10^{3}$ & $1^{\prime} 10^{2}$ & $1^{\prime} 10^{1}$ & $1^{\prime} 10^{\circ}$ \\
\hline 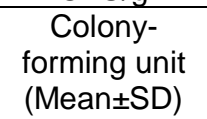 & TNTC $^{1}$ & TNTC & TNTC & TNTC & TNTC & TNTC & TNTC & $147 \pm 12.7$ & $13 \pm 1.4$ & $2 \pm 1.4$ \\
\hline Vi amplicons $^{2}$ & 2 & + & + & + & + & + & + & + & + & -3 \\
\hline
\end{tabular}


Malays. J. Microbiol. Vol 14(6) Special Issue 2018, pp. 483-489 DOI: http://dx.doi.org/10.21161/mjm.1461806

\section{CONCLUSION}

The protocol developed in this study is rapid, sensitive and specific for the early diagnosis and chronic carrier detection of typhoid fever. Further application of this approach will be targeted to clinical blood, urine and stool samples in order to obtain data on clinical validation performance.

\section{ACKNOWLEDGEMENTS}

The authors would like to thank the Director General of the Ministry of Health Malaysia for his permission to publish this article. The authors would also like to thank the Director of National Public Health Laboratory for his kind continuous support. We thank all team members for their commitment in this research. This work was funded and supported by Ministry of Health Malaysia.

\section{REFERENCES}

Abdullah, J., Saffie, N., Sjasri, F. A., Husin, A., AbdulRahman, Z., Ismail, A., Aziah, I. and Mohamed, M. (2014). Rapid detection of Salmonella Typhi by loopmediated isothermal amplification (LAMP) method. Brazilian Journal of Microbiology 45, 1385-1391.

Ali, A., Haque, A., Haque, A., Sarwar, Y., Mohsin, M., Bashir, S. and Tariq, A. (2009). Multiplex PCR for differential diagnosis of emerging typhoidal pathogens directly from blood samples. Epidemiology \& Infection 137, 102-107.

Ambati, S. R., Nath, G. and Das, B. K. (2007). Diagnosis of typhoid fever by polymerase chain reaction. The Indian Journal of Pediatrics 74, 909-913.

Bhutta, Z. A. (2006). Current concepts in the diagnosis and treatment of typhoid fever. British Medical Journal 333, 78-81.

Brooks, W. A., Hossain, A., Goswami, D., Sharmeen, A. T., Nahar, K., Alam, K., Ahmed, N., Naheed, A., Nair, G. B., Luby, S. and Breiman, R. F. (2005). Bacteremic typhoid fever in children in an urban slum, Bangladesh. Emerging Infectious Diseases 11, 326329.

Chaudhry, R., Chandel, D. S., Verma, N., Singh, N., Singh, P. and Dey, A. B. (2010). Rapid diagnosis of typhoid fever by an in-house flagellin PCR. Journal of Medical Microbiology 59, 1391-1393.

Crump, J. A. and Mintz, E. D. (2010). Global trends in typhoid and paratyphoid fever. Clinical Infectious Diseases 50, 241-246.

Crump, J. A., Luby, S. P. and Mintz, E. D. (2004). The global burden of typhoid fever. Bulletin of the World Health Organization 82, 346-353.

Elizaquivel, P. and Aznar, R. (2008). A multiplex RTiPCR reaction for simultaneous detection of Escherichia coli O157: H7, Salmonella spp. and Staphylococcus aureus on fresh, minimally processed vegetables. Food Microbiology 25, 705-713.

Fan, F., Du, P., Kan, B. and Yan, M. (2015). The development and evaluation of a loop-mediated isothermal amplification method for the rapid detection of Salmonella enterica serovar Typhi. PLOS ONE 10(4): e0124507.

Farrell, J. J., Doyle, L. J., Addison, R. M., Reller, L. B., Hall, G. S. and Procop, G. W. (2005). Broad-range (Pan) Salmonella and Salmonella serotype Typhispecific Real-Time PCR assays: Potential tools for the clinical microbiologist. American Journal of Clinical Pathology 123, 339-345.

Feasey, N. A., Dougan, G., Kingsley, R. A., Heyderman, R. S. and Gordon, M. A. (2012). Invasive non-typhoidal Salmonella disease: An emerging and neglected tropical disease in Africa. The Lancet 379, 2489-2499.

Germini, A., Masola, A., Carnevali, P. and Marchelli, R. (2009). Simultaneous detection of Escherichia coli 0175: H7, Salmonella spp., and Listeria monocytogenes by multiplex PCR. Food Control 20, 733-738.

Hashimoto, Y., Itho, Y., Fujinaga, Y., Khan, A. Q., Sultana, F., Miyake, M., Hirose, K., Yamamoto, H. and Ezaki, T. (1995). Development of nested PCR based on the $V i a B$ sequence to detect Salmonella Typhi. Journal of Clinical Microbiology 33, 775-777.

Hashimoto, Y., Li, N., Yokoyama, H. and Ezaki, T. (1993). Complete nucleotide sequence and molecular characterization of $\mathrm{ViaB}$ region encoding $\mathrm{Vi}$ antigen in Salmonella Typhi. Journal of Bacteriology 175, 44564465.

Hatta, M. and Smits, H. L. (2007). Detection of Salmonella Typhi by nested polymerase chain reaction in blood, urine, and stool samples. The American Journal of Tropical Medicine and Hygiene 76, 139-43.

Hirose, K., Hashimoto, A., Tamura, K., Kawamura, Y., Ezaki, T., Sagara, H. and Watanabe, H. (2002). DNA sequence analysis of DNA gyrase and DNA topoisomerase IV quinolone resistance-determining regions of Salmonella enterica serovar Typhi and serovar Paratyphi A. Antimicrobial Agents and Chemotherapy 46, 3249-3252.

Kolyva, S., Waxin, H. and Popoff, M. Y. (1992). The Vi antigen of Salmonella Typhi: Molecular analysis of the viaB locus. Journal of General Microbiology 138(2), 297-304.

Kumar, A., Balachandran, Y., Gupta, S. and Khare, S. (2010). Quick PCR based diagnosis of typhoid using specific genetic markers. Biotechnology Letters 32, 707-712.

Kumar, S., Balakrishna, K. and Batra, H. V. (2006). Detection of Salmonella enterica serovar Typhi ( $S$. Typhi) by selective amplification of invA, viaB, flic-d and prt genes by polymerase chain reaction in mutiplex format. Letters in Applied Microbiology 42, 149-154.

Kumar, S., Rizvi, M. and Berry, N. (2008). Rising prevalence of enteric fever due to multidrug-resistant Salmonella: An epidemiological study. Journal of Medical Microbiology 57, 1247-1250. 
Levy, H., Diallo, S., Tennant, S. M., Livio, S., Sow, S. O., Tapia, M., Fields, P. I., Mikoleit, M., Tamboura, B., Kotloff, K. L. and Lagos, R. (2008). A PCR method to identify Salmonella enterica serovars Typhi, Paratyphi A and Paratyphi B among Salmonella isolates from the blood of patients with clinical enteric fever. Journal of Clinical Microbiology 46, 1861-1866.

Massi, M. N., Gotoh, A., Bishnu, A., Kawabata, M., Shirakawa, T. and Hatta, M. (2003). Rapid diagnosis of typhoid fever by PCR assay using one pair of primers from flagellin gene of Salmonella typhi. Journal of Infection and Chemotherapy 9, 233-237.

Moganedi, K. L., Goyvaerts, E. M., Venter, S. N. and Sibara, M. M. (2007). Optimisation of the PCR-invA primers for the detection of Salmonella in drinking and surface waters following a pre-cultivation step. Water SA 33, 195-202.

Naheed, A., Ram, P. K., Brooks, W. A., Mintz, E. D., Hossain, M. A., Parsons, M. M, Luby, S. P. and Breiman, R. F. (2008). Clinical value of Tubex $^{\mathrm{TM}}$ and Typhidot $\AA$ rapid diagnostic tests for typhoid fever in an urban community clinic in Bangladesh. Diagnostic Microbiology and Infectious Disease 61, 381-386.

Nakhla, I., El Mohammady, H., Mansour, A., Klena, J. D., Hassan, K., Sultan, Y., Pastoor, R., Abdoel, T. H. and Smits, H. (2011). Validation of the Dri-Dot Latex agglutination and IgM lateral flow assays for the diagnosis of typhoid fever in an Egyptian population. Diagnostic Microbiology and Infectious Disease $\mathbf{7 0}$, 435-441.

Nizami, S. Q., Bhutta, Z. A., Siddiqui, A. and Lubbad, L. (2006). Enhanced detection rate of typhoid fever in children in a periurban slum in Karachi, Pakistan using polymerase chain reaction technology. Scandinavian Journal of Clinical and Laboratory Investigation 66, 429-436.

Oikarinen, S., Tauriainen, S., Viskari, H., Simell, O., Knip, M., Virtanen, S. and Hyöty, H. (2009). PCR inhibition in stool samples in relation to age of infants. Journal of Clinical Virology 44, 211-214.

Parikh, R., Mathai, A., Parikh, S., Sekhar, G. C. and Thomas, R. (2008). Understanding and using sensitivity, specificity and predictive values. Indian Journal of Ophthalmology 56, 45-50.

Park, S. H., Kim, H. J., Cho, W. H., Kim, J. H., Oh, M. H., Kim, S. H., Lee, B. K., Ricke, S. C. and Kim, H. Y. (2009). Identification of Salmonella enterica subspecies I, Salmonella enterica serovars Typhimurium, Enteritidis and Typhi using multiplex PCR. FEMS Microbiology Letters 301, 137-146.

Parkhill, J., Dougan, G., James, K. D., Thomson, N. R., Pickard, D., Wain, J., ... and Barrell, B. G. (2001). Complete genome sequence of a multiple drug resistant Salmonella enterica serovar Typhi CT18. Nature 413, 848-852.

Parry, C. M., Wijedoru, L., Arjyal, A. and Baker, S. (2011). The utility of diagnostic tests for enteric fever in endemic locations. Expert Review of Anti-infective Therapy 9, 711-725.
Pui, C. F., Wong, W. C., Chai, L. C., Lee, H. Y., Noorlis, A., Zainazor, T. C., Tang, J. Y., Ghazali, F. M., Cheah, Y. K., Nakaguchi, Y. and Nishibuchi, M. (2011). Multiplex PCR for the concurrent detection and differentiation of Salmonella spp., Salmonella Typhi and Salmonella Typhimurium. Tropical Medicine and Health 39, 9-15.

Schadich, E., Dzubak, P. and Hajduch, M. (2016). Role of Salmonella Typhi Vi antigen and secretory systems on immune response. Current Pharmaceutical Design 22, 6251-6260.

Schrader, C., Schielke, A., Ellerbroek, L. and Johne, R. (2012). PCR inhibitors-occurrence, properties and removal. Journal of Applied Microbiology 113, 10141026.

Sharma, K. B. and Arya, S. C. (1995). Detection of Salmonella Typhi by nested PCR based on the ViaB sequence. Journal of Clinical Microbiology 33, 775777.

Song, J. H., Cho, H., Park, M. Y., Na, D. S., Moon, H. B. and Pai, C. H. (1993). Detection of Salmonella Typhi in the blood of patients with typhoid fever by polymerase chain reaction. Journal of Clinical Microbiology 31, 1439-1443.

Tennant, S. M., Toema, D., Qamar, F., Iqbal, N., Boyd, M. A., Marshall, J. M., Blackwelder, W. C., Wu, Y., Quadri, F., Khan, A. and Aziz, F. (2015). Detection of typhoidal and paratyphoidal Salmonella in blood by real-time polymerase chain reaction. Clinical Infectious Diseases 61, 241-250.

Wain, J., Bay, P. V. B., Vinh, H., Duong, N. M., Diep, T. S., Walsh, A. L., Parry, C. M., Hasserjian, R. P., Ho, V. A., Hien, T. T. and Farrar, J. (2001). Quantitation of bacteria in bone marrow from patients with typhoid fever: Relationship between counts and clinical features. Journal of Clinical Microbiology 39, 15711576.

Wain, J., Hendriksen, R. S., Mikoleit, M. L., Keddy, K. H. and Ochiai, R. L. (2015). Typhoid fever. Lancet 385, 1136-1145.

Wang, R. F., Cao, W. W. and Cerniglia, C. E. (1997). A universal protocol for PCR detection of 13 species of foodborne pathogens in foods. Journal of Applied Microbiology 83, 727-736.

WHO (2003). Background document: The diagnosis, treatment and prevention of typhoid fever.

Zaki, S. A. and Karande, S. (2011). Multidrug-resistant typhoid fever: A review. The Journal of Infection in Developing Countries 5, 324-337.

Zhang, J. Y., Dong, L. W., Ren, Q., Wang, X. Z., Yang, Y., Zhou, W., Zhu, C. H., Meng, X. and Zhu, G. Q. (2014). Simple and rapid detection of Salmonella by direct PCR amplification of gene fimW. Current Microbiology 69, 429-435.

Zhu, Q., Lim, C. K. and Chan, Y. N. (1996). Detection of Salmonella Typhi by polymerase chain reaction. Journal of Applied Microbiology 80, 244-251. 